\title{
Behavior of Damaged Exterior RC Beam-Column Joints Strengthened by CFRP Composites
}

\section{Abstract}

This paper presents an experimental investigation on the behavior of retrofitted beam-column joints subjected to reversed cyclic loading. The experimental program comprises 8 external beamcolumn joint connection subassemblages tested in 2 phases; one was the damaging phase and second was the repairing phase. The Beam-column joints were designed only for gravity loads. The joints had no beam-column joint transverse reinforcement and special stirrups in beam and column critical zones. These NonSeismically designed (NS) joints were damaged with different levels at the first phase of the experiment. In the second phase, the damaged joints were strengthened with externally bonded carbon-fibre-reinforced polymers (C-FRP) sheets. From the observed responses of the examined specimens it can be deduced that the technique of externally bonded retrofitting (EBR) using CFRP sheets is appropriate for the rehabilitation of the joints seismic capacity. This technique had a significant improvement of the energy dissipation and the performance level and finally it leads to improved type of damages compared with the damage modes of the specimens during the initial loading. Shortcomings of the application of C-FRP sheets for practical use are also pointed out.

\section{Keywords}

Damaged Concrete connection, CFRP laminates, Rehabilitation, Performance level, Ductility.

\author{
Ebrahim Zamani Beydokhty ${ }^{a}$ \\ Hashem Shariatmadar ${ }^{b}$ * \\ ${ }^{a}$ Ph.D student, Department of Civil \\ Engineering, Faculty of Engineering, \\ Ferdowsi University of Mashhad, Iran \\ (FUM), Postal Code 9177948944, P.O. \\ Box 1111, Mashhad, Iran Email: \\ eb.zamani@stu.um.ac.ir \\ b Associate Professor, Department of \\ Civil Engineering, Faculty of Engineer- \\ ing, Ferdowsi University of Mashhad, \\ Iran
}

(Corresponding Author) Email: Shariatmadar@um.ac.ir

http://dx.doi.org/10.1590/1679-78252258

Received 29.06.2015

Accepted 24.01.2016

Available online 17.02.2016

\section{INTRODUCTION}

The repair and rehabilitation of reinforced concrete structures damaged by earthquakes are challenging fields of study in earthquake engineering, which have been developed during the last two decades. Research in this area is essential since engineers in seismic-prone regions often face the problem of designing the repair or strengthening of damaged buildings without quantitative guidance. lateral load carrying capacity of multi-storey reinforced concrete frames that were built prior 
to the 1970's are often insufficient due to non-ductile reinforcement detailing, which included either insufficient or no beam-column joint transverse reinforcement. On the other hand, the failure of these non-seismically designed joints may lead to general failure of the entire structure (Park and Paulay 1975).

In the last two decades, efficient and economical methods for strengthening of the joints have been especially investigated. Among all of these methods, Fiber reinforced polymer laminates have been extensively used because of lots of mechanical properties such as high strength to weight ratio, corrosion resistance and ease of fabrication (Rizkalla, Hassan et al. 2003). Fibre-reinforced composite laminates have been used as confining jacketing systems for the retrofitting of underdesigned or damaged reinforced concrete members that could be benefited from confinement of the concrete.

In the recent years, a lot of researches have been done on how using FRP laminates affect the behavior of the concrete joints. There are also considerable experimental studies on the seismic parameters of the upgraded or repaired connections. Lee et al. (2002) investigated the effect of the simultaneously using of carbon and glass composites. Antonopoulos and Triantafillou (2002) and Bing Li et al. (2010) investigated the rehabilitation of the concrete connections with carbon and glass composites and compared the cyclic behaviors. Research of Balsamo et al. (2005) about the effect of the CFRP laminates on the behavior of a full scale structure with dual system of moment frame and shear wall under cyclic and seismic loading have shown the improvement of the structures' behavior.

In this research, an effort to use carbon-fiber-reinforced plastic (C-FRP) sheets in the improvement of the seismic capacity and stiffness of reinforced concrete exterior beam-column connections is presented. The experimental program comprises 8 external beam-column joint connection subassemblages with $2 / 3$ scale tested in 2 phases; one was the damaging phase and second was the repairing phase. The beam-column joints were designed for gravity loading. The joints had no beam-column joint transverse reinforcement and special stirrups in beam and column critical zones. These Non-Seismically designed (NS) joints were damaged up to the different levels at the first phase of the experiment. In the second phase, the damaged joints were strengthened with externally bonded carbon-fibre-reinforced plastics (C-FRP) sheets.

The specimen NS5 was tested until storey drift of 5\%. While the specimens NS1, NS2 and NS3 tested until 1\%, $1.5 \%$ and $3 \%$ storey drift, respectively. In the following, four non-seismically designed joint mentioned above were retrofitted with CFRP laminates so called NS1R, NS2R, NS3R and NS5R. Finally, the retrofitted joints were tested again until 5\% storey drift. The results are presented as tables and hysteresis response curves, and eventually evaluated and compared.

\section{EXPERIMENTAL PROGRAM}

\subsection{Test Specimen Details}

The beam of the joint subassemblage is taken to the mid-span of the bay, while the column is taken from the mid-height of one storey to the mid-height of the next storey. The sub-standard beamcolumn joint (NS5) was designed as per the current CSA A23.3-04 (2004). Beam and column cross sections with the $2 / 3$ scale had the 30x40 $\mathrm{cm}$ and 30x30 cm dimensions, respectively. The length of the beam from mid span to the side of column was $1400 \mathrm{~mm}$ and the length of the column from the 
mid height of the bottom floor to the mid height of the higher floor was $2300 \mathrm{~mm}$. The maximumsize coarse aggregate used in the concrete was $25 \mathrm{~mm}$. The average compressive strength of concrete at the time of the test was 38.5 MPa. The detailing of reinforcing in beam-column joint is presented in Figure 1. $\varnothing 10$ and $\varnothing 18$ rebars, were used as stirrups and longitudinal reinforcement in the specimens, with yield strengths of 510 and $533 \mathrm{MPa}$, respectively.

The longitudinal rebars for the columns were $8 \varnothing 18$ bars corresponding to a $1.7 \%$ reinforcement ratio. The $\varnothing 10$ stirrups were spaced at $200 \mathrm{~mm}$ over the entire height of the column. No transverse reinforcement was used in the joint area.

The top and bottom longitudinal reinforcements of the beam were $4 \varnothing 18$ bars each corresponding to a $2.26 \%$ reinforcement ratio. The transverse reinforcement of the beam was $\varnothing 10$ rectangular ties starting at $50 \mathrm{~mm}$ from the face of the column. The ties were spaced at $150 \mathrm{~mm}$ along the beam.

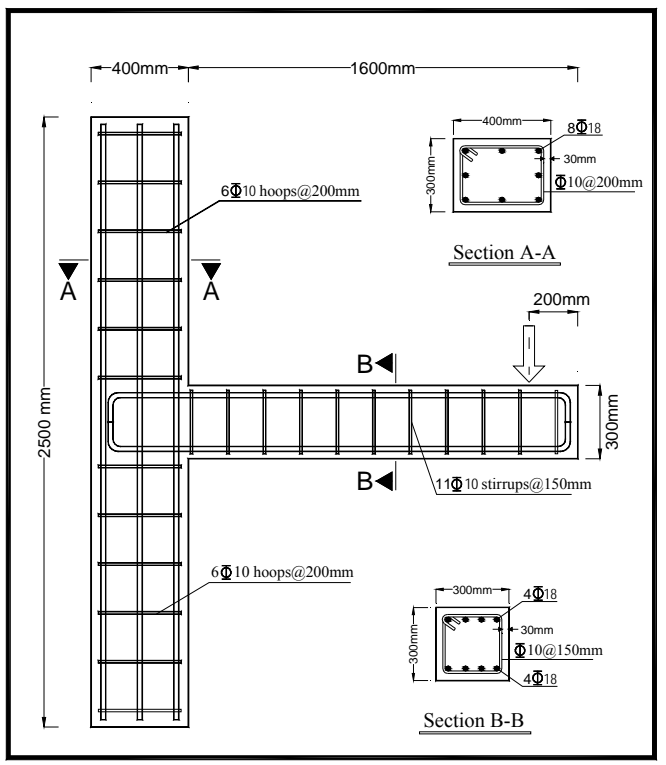

Figure 1: Detailing of reinforcing in beam-column joint.

\subsection{Repaired Specimens}

Carbon fiber-reinforced polymer (CFRP) composite material was used to strengthen the joints after they had sustained extensive damage during Phase I testing. From the manufacturer data sheet, the tensile strength, elastic modulus, and ultimate strain of the fabric with an average thickness of mm were $4950 \mathrm{MPa}, 240 \mathrm{GPa}$, and 1.5\%, respectively.

Based on the test results of specimen NS5, the storey drifts corresponded to structural performance levels (IO, LS and CP) were obtained. The net beam rotation within $600 \mathrm{~mm}$ adjacent to column face was measured during the test according to FEMA 273 (1997). Thus, the tested NSGrade specimens up to 1\% (NS1), 1.5\% (NS2) and 3\% (NS3) storey drifts were selected for IO, LS and $\mathrm{CP}$ structural performance levels, respectively.

Based on previous researches on rehabilitation of connections (Pantelides, Okahashi et al. 2008, Ilki, Bedirhanoglu et al. 2010) and damage mechanism of NS5 specimen, the detailing shown in the 
Figure 2 was used for the repair of connections. Flexural retrofitting of Beam and column of the specimens were gained by either one or two L-shaped CFRP laminates according to ACI440.2R-08 (2008). Besides, the NS specimens was shear retrofitted using one layer sheet with the length of 500 $\mathrm{mm}$ on the two parallel sides of the column with the $90^{\circ}$ angle relative to beam axis. Also, a $500 \mathrm{~mm}$ one layer U-shaped of the CFRP laminate on the three free faces of the joint with the $0^{\circ}$ angle perpendicular to previous layer was attached to improve the confinement, strength and deformability of the joint.

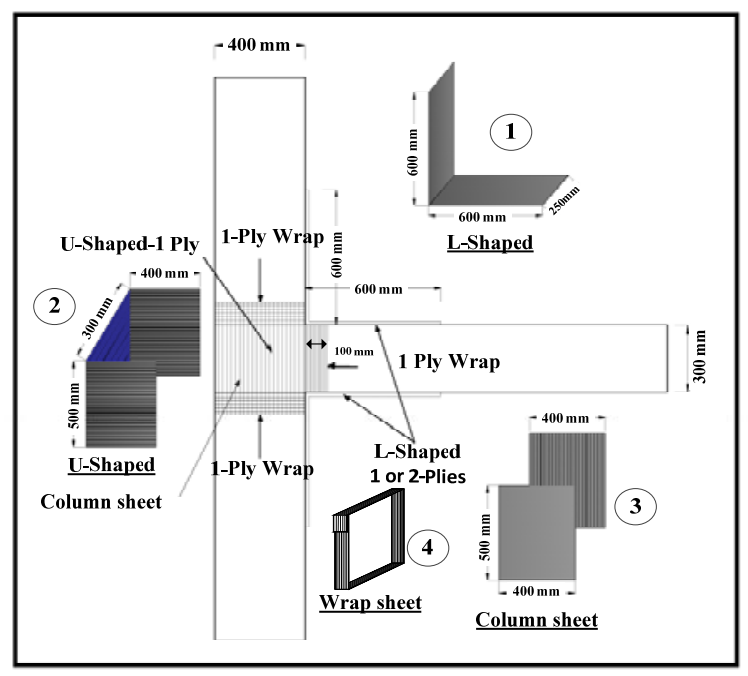

Figure 2: Application of CFRP laminates for the strengthening of specimens.

\subsection{Test Set-Up and Loading History}

The experimental setup for specimens is shown in Figure 3: Test-set up.. The specimens were rotated $90^{\circ}$ vertically, so the column placed on the floor of the laboratory and the beam was projected from the floor. The Figure 3: Test-set up. shows the fastened specimen on the strong floor.

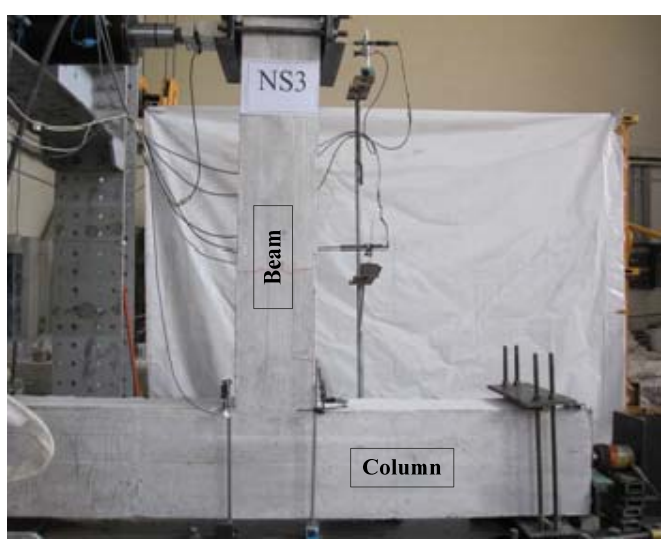

(a)

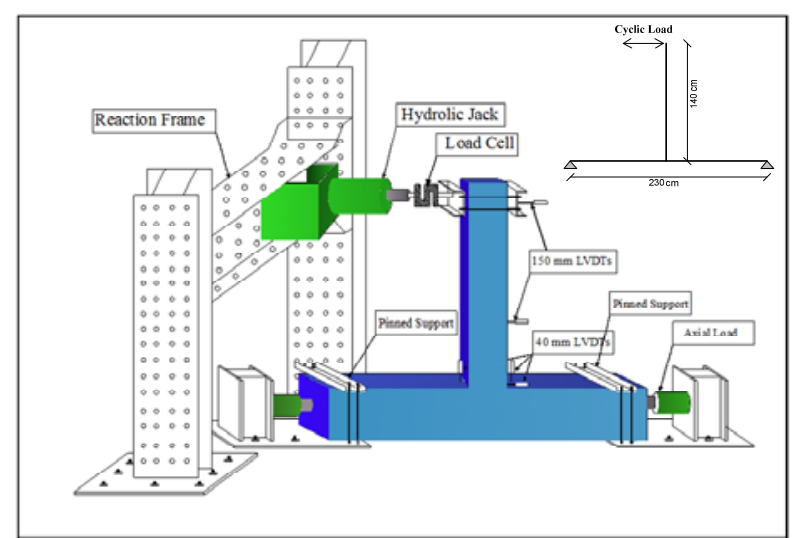

(b)

Figure 3: Test-set up. 
The end of beam and columns were points of contra flexure due to lateral loading of structure. The specimens were pin-supported at the mid height of the column connected to the reaction strong floor. A constant axial load about $70 \mathrm{kN}$ was applied at the ends of column. Horizontal displacements were applied at beam mid span through a pin-ended double-acting $800 \mathrm{kN}$ hydraulic actuator.

Cyclic loading was applied to the tip of the beam according to the loading history displayed in Figure 4. Specimens were tested under a load-controlled cyclic in elastic range followed by displacement-controlled cyclic load history based on the inter-storey drift which represented a severe load condition for beam to column joint.

The test loading pattern is based on drift rather than ductility increments because the ductility can be difficult to define for retrofitted systems other than conventionally reinforced concrete or steel structures.

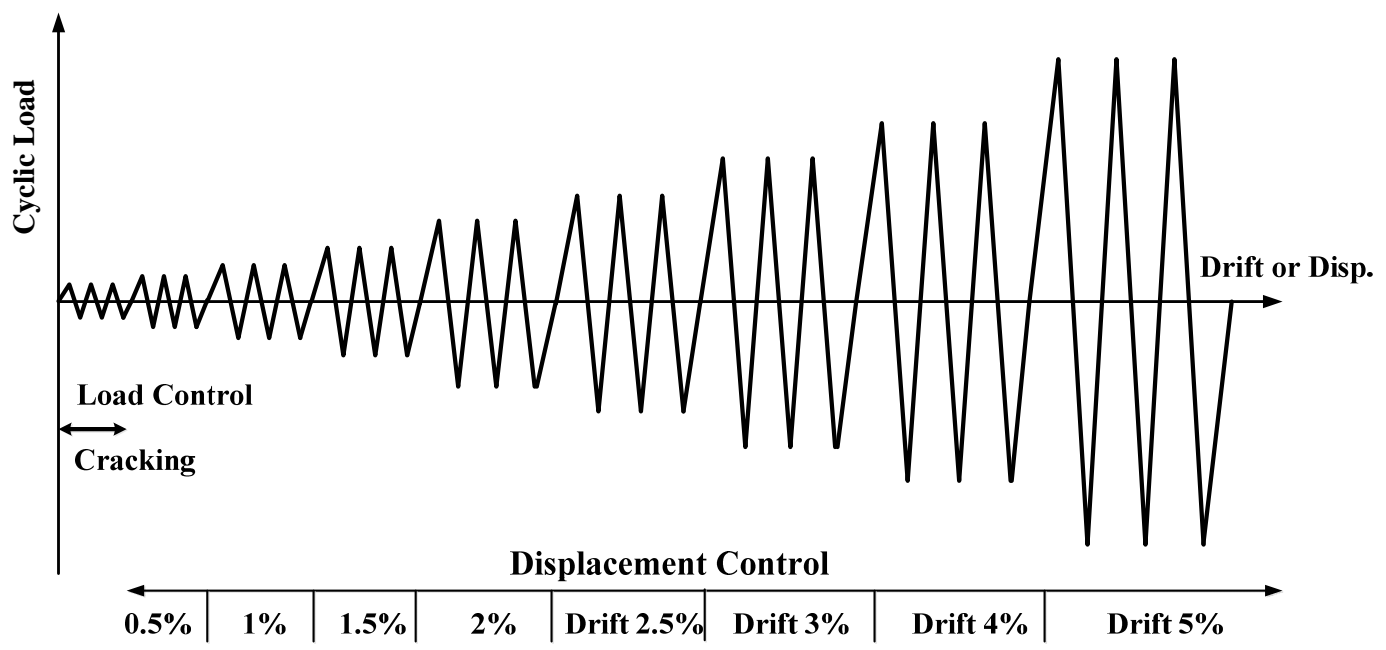

Figure 4: Load history for the reversed cyclic load test.

\subsection{Instrumentation and Data Acquisition}

Specimens were instrumented with displacement and load transducers. Data from different monitoring devices such as load cells and displacement transducers channels connected to the computer attached data acquisition unit to record data at a constant time interval of 0.5 second. The measured loads were the column's axial load and the beam's tip load.

Five linear variable displacement transducers (LVDT) were used to measure the displacement at various locations on the specimen as shown in Figure 3-b. One 150-mm LVDT measured the beam tip displacement. Three $40 \mathrm{~mm}$ LVDTs were attached on the surface of beam and column at the vicinity of joint, and one $150 \mathrm{~mm}$ LVDT was mounted on the beam surface at a distance of 600 mm from column side for measuring the beam rotation and curvature. 


\section{TEST RESULTS}

\subsection{Phase I Test Results}

NS5 specimen is the reference for specimens with non-seismic details. The test was started in elastic loading stage as load control. So, the loading was performed until the occurrence of the first crack on the beam in the vicinity of the column. The first bending crack appeared in the $15 \mathrm{kN}$ load. After performing three repetitive cycles in this load, the load increased to $35 \mathrm{kN}$ in the $0.5 \%$ drift. At this moment, the width of the bending crack was measured $0.7 \mathrm{~mm}$. Increasing the load gradually, the structure entered the nonlinear behavior stage and loading was performed in the drifts $1 \%, 1.5 \%, 2 \%, 2.5 \% 3 \%, 4 \%$ and $5 \%$ respectively as shown in Figure 5.

In the drift of $1.5 \%$, bending cracks extended first in the $79 \mathrm{kN}$ forward loading and then they extended in the backward loading along the longitudinal reinforcements. As approved after with the test results, the yielding of the beam's longitudinal reinforcement was occurred in $1.5 \%$ storey drift. At this moment, the crack's width increased to $1 \mathrm{~mm}$. In the subsequent loading cycles in $90 \mathrm{kN}$ load, diagonal cracks were created inside the joint and the width of the bending cracks increased to $2 \mathrm{~mm}$. Finally, the width of these bending cracks was measured $6 \mathrm{~mm}$ in the drift of $5 \%$. At the end of the test in $86 \mathrm{kN}$ load, the concrete in the compressive zone crushed on the beam and collapsed.

Due to the absence of transverse reinforcement confining the joint and also absence of special stirrup in the critical zones of the beam and column, diagonal cracks grew in the joint and concentrated in the beam's critical zone. The crack pattern in the last loading cycle and hysteresis curve of load-storey drift of NS5 specimen are displayed in Figure 5.

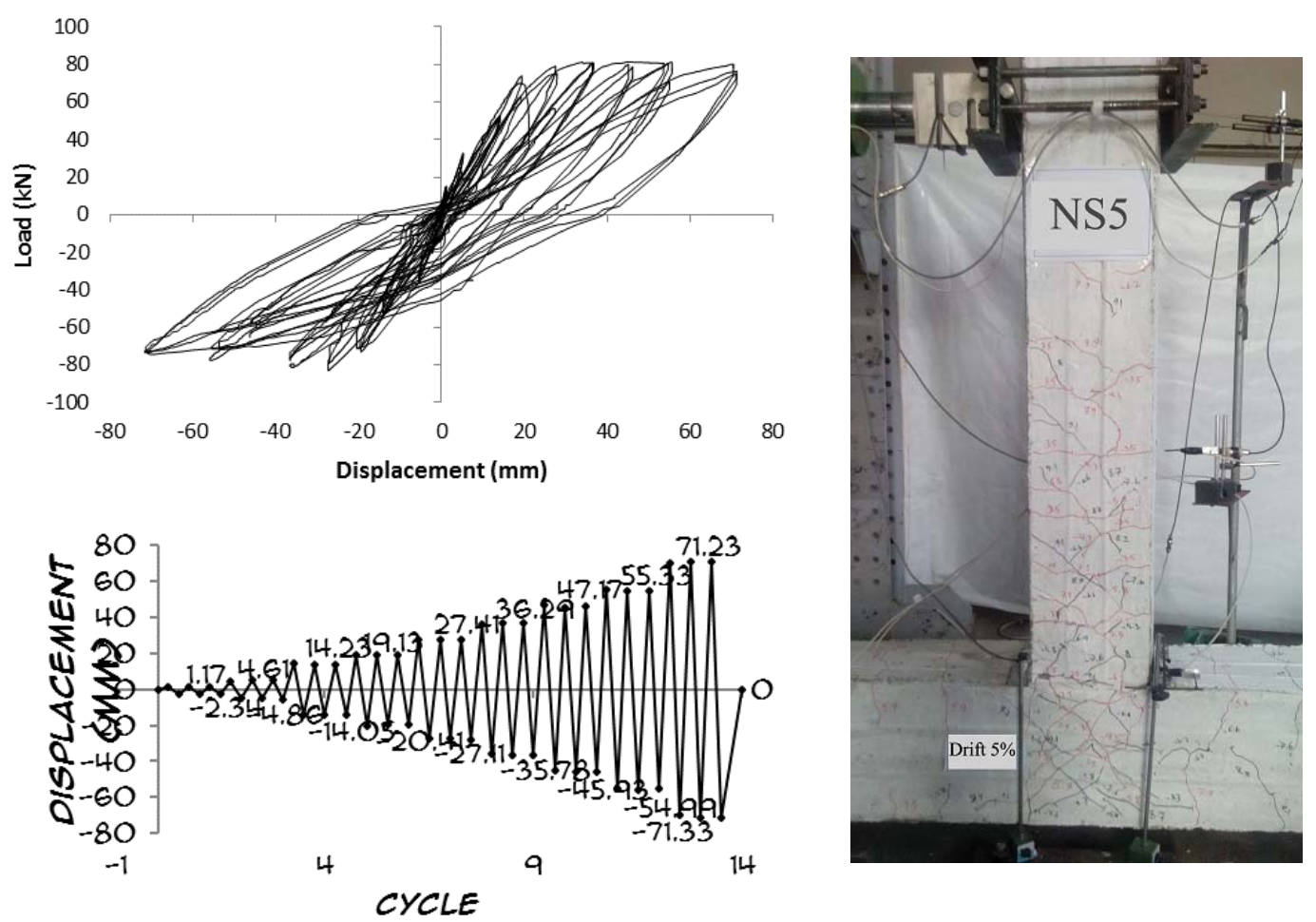

Figure 5: Hysteresis curve, loading history and crack pattern of specimen NS5. 
According to the NS5 specimen test results as will be presented in the next sections, the drifts $1 \%, 1.5 \%$ and $3 \%$ were obtained as the IO, LS and CP performance levels of the specimens based FEMA 273 (1997), respectively. Initial damages were applied on the specimens NS1, NS2 and NS3 up to $1 \%, 1.5 \%$ and $3 \%$ storey drift, respectively before the strengthening. The geometrical characteristics and the materials used in the strengthened joints were exactly similar to NS5 specimen. The hysteresis curves of beam tip load-displacement for specimens NS1, NS2 and NS3 are plotted in Figure 6.
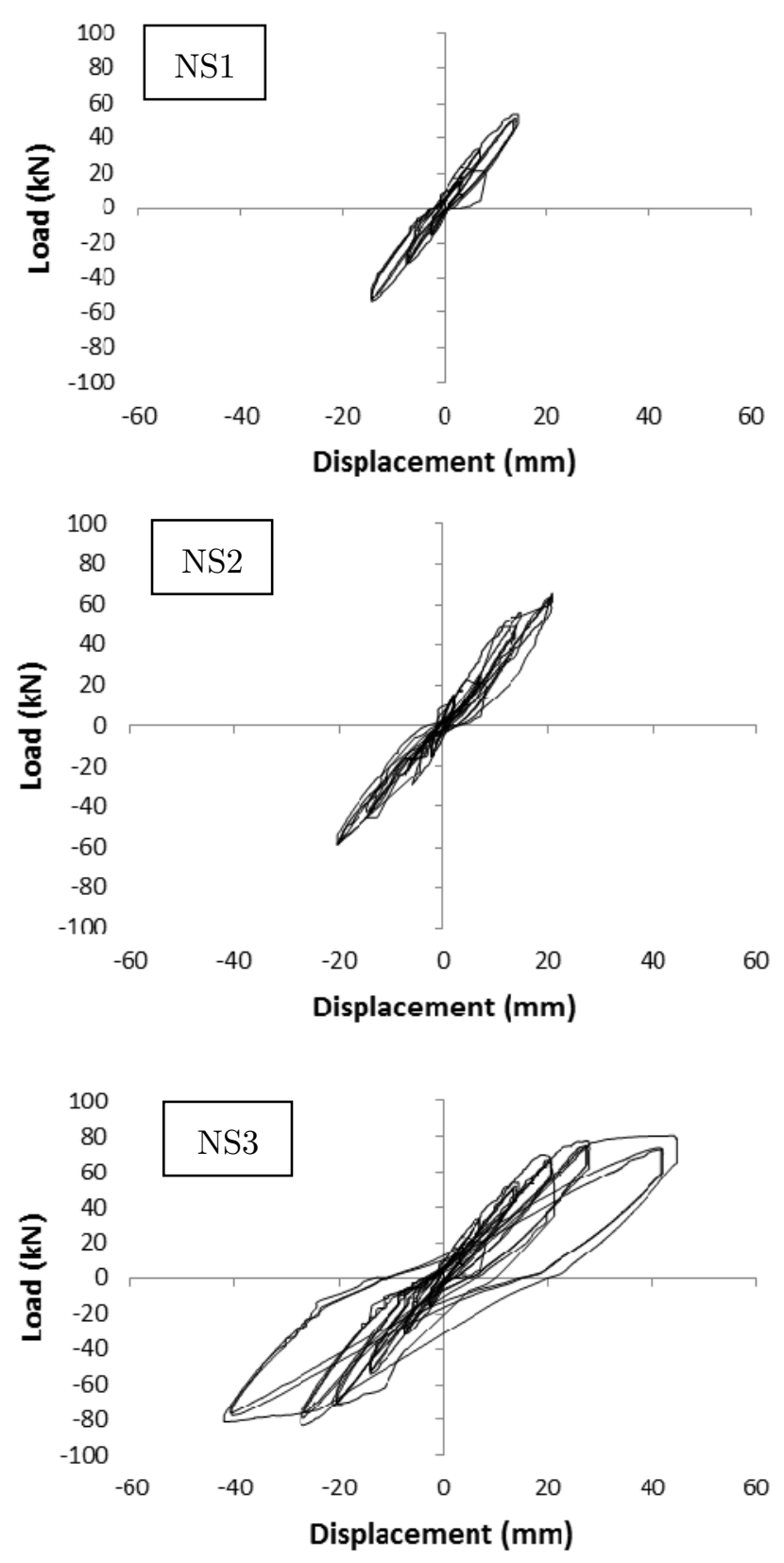

Figure 6: Hysteresis curves of specimens NS1, NS2 and NS3. 


\subsection{Phase II Test Results}

After finishing the phase 1, the damaged specimens were strengthened and then were tested under reversed cyclic load, once more. The retrofitted specimens were named NS1R, NS2R, NS3R and NS5R. The NS1 specimen was damaged up to $1 \%$ storey drift in the first phase of experiment. The load was removed and NS1 specimen was strengthened by one ply FRP sheet under and above the beam and around the joint area according to Figure 2 (specimen NS1R). Hysteresis curves for beam tip load-displacement of strengthened specimens are plotted in Figure 7. The load-carrying capacity of specimen NS1R increased up to an average 5\% compared to the final capacity of NS5 specimen up to the drift $5 \%$ without any failure or separation of FRP layers.

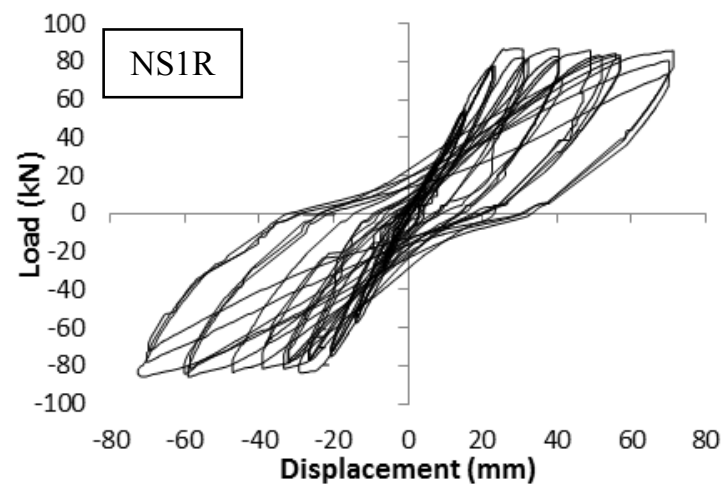

(a)

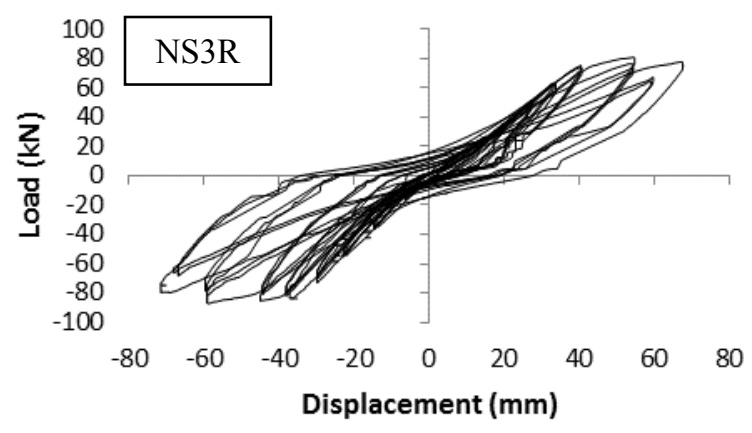

(c)

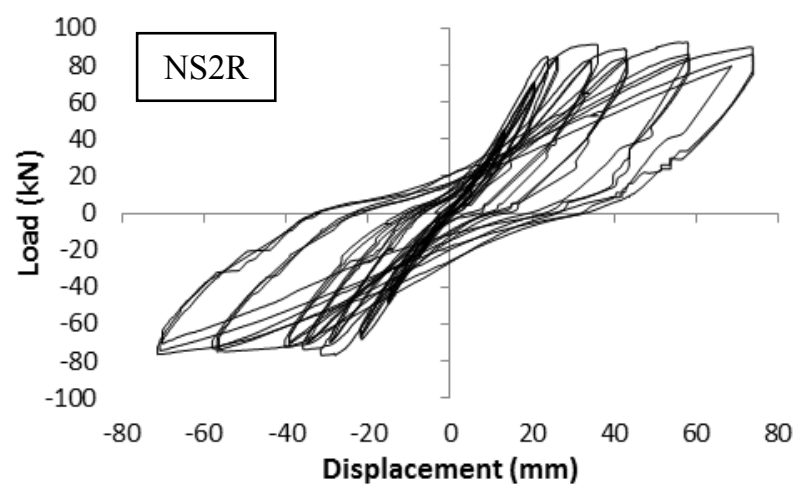

(b)

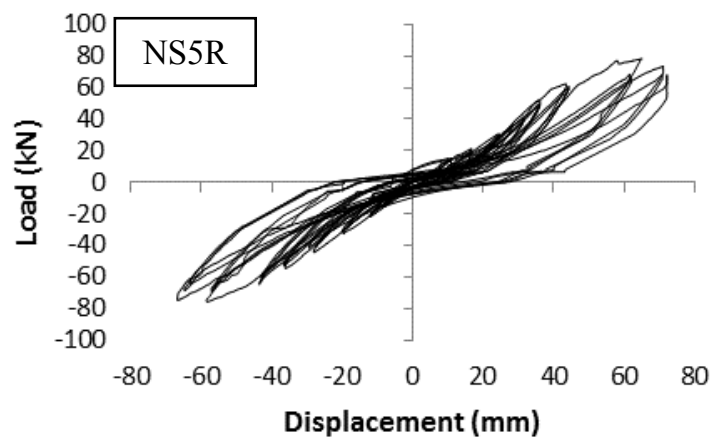

(d)

Figure 7: Load-displacement hysteresis curves of specimens.

NS2 specimen was damaged up to $1.5 \%$ storey drift in the first phase of experiment. The load was removed and NS2 specimen was strengthened by one ply FRP sheet under and above the beam and around the joint area according to Figure 2 (specimen NS2R). Similar to NS1R specimen according to Figure 7, NS2R specimen increased the load-carrying capacity on average to $3 \%$ compared to the ultimate capacity of NS5 specimen up to the drift $5 \%$ without any failure of FRP layers. In this specimen after the drift $2 \%$, shear cracks extended from the end of the L-shaped FRP sheets top and bottom the beam. In the drift 3\%, the L-shaped FRP layer buckled from the beam 
surfaces in several points. Finally, the L-shaped layer at the right hand side of the beam was then ruptured in the drift $4 \%$.

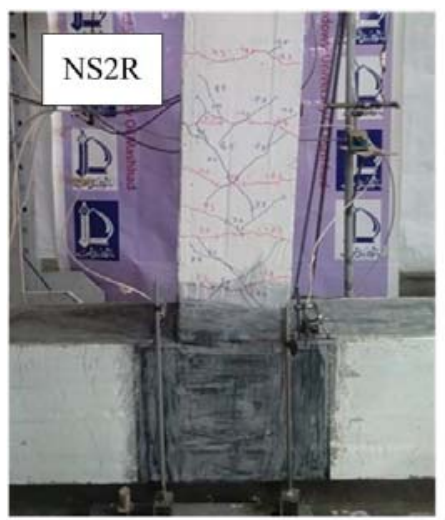

(b)

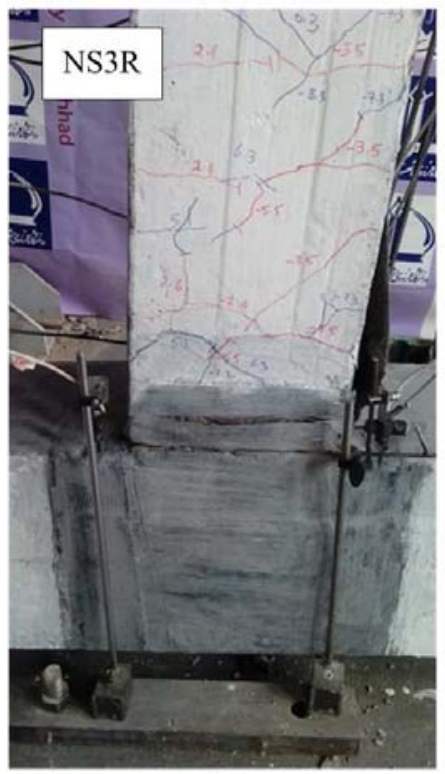

(c)

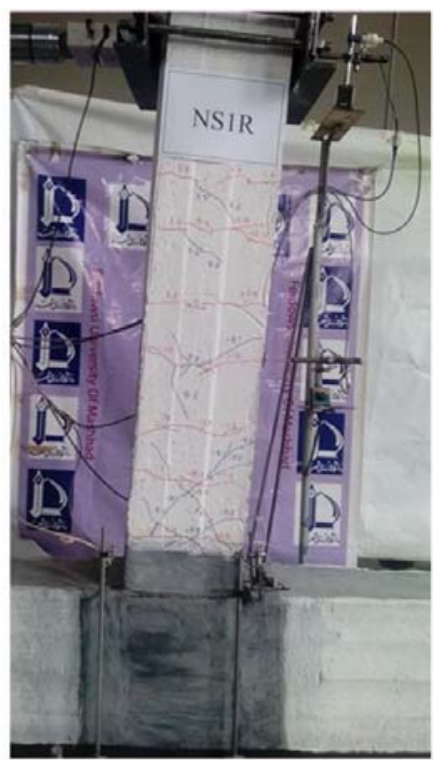

(a)

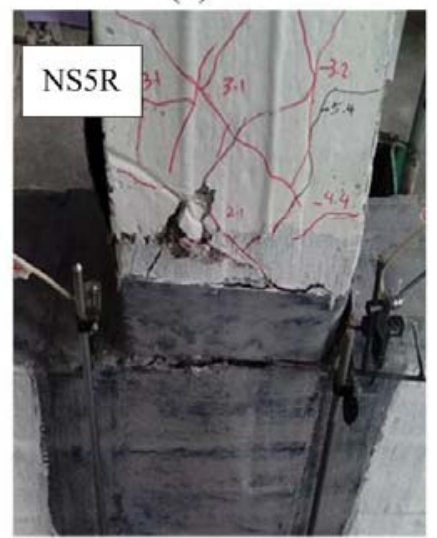

(d)

Figure 8: Crack pattern of strengthened specimens.

Based on the test results of the NS5 specimen, it became clear that the drift $3 \%$ is equivalent to the last level of damage according to the building code for the tested joints, at which the specimen can preserve its stability after a high damage. Hence, after the initial damage up to the $3 \%$ drift, NS3 specimen was unloaded and was then strengthened for bending by two FRP layers top and bottom of the beam and was shear strengthened by one layer around the joint (specimen NS3R).

Since the initial damage was high in specimen NS3R and despite the injection of epoxy mortar inside the opened cracks on the beam in the vicinity of the column, the cracks began to open very soon so that their width was measured $1.1 \mathrm{~mm}$ in the drift $2 \%$. Increasing the load, the crack increased to $1.8 \mathrm{~mm}$ in the drift $2.5 \%$, to $2 \mathrm{~mm}$ in the drift $3 \%$ and to $5 \mathrm{~mm}$ in the drift $4 \%$. In addi- 
tion in the drift 3\%, L-shaped layers of the beam also buckled under compressive stresses and the wraps on the beam also tore at the corners. At the drift 4\%, the L-shaped buckling increased and the wrap of the beam was completely cut. Although NS3R specimen recovered the joint's lost capacity and even tolerated $2 \%$ more than NS5 specimen, it must be mentioned that the NS3R specimen's behavior is smoother than the previous specimens that shows the reduction of stiffness and strength of the specimen compared to the previous reference and strengthened specimens (see Figure 7$)$.

NS5R specimen had the highest level of damage up to 5\% storey drift. After injecting wide cracks by epoxy mortar and strengthening by FRP layers, it was retested under reversed cyclic load.

The specimen's behavior was similar to NS3R specimen in terms of cracking but with a higher intensity. At first in the drift 1\%, bending cracks began to open in the vicinity of the column. In drift $1.5 \%$, L-shaped beams buckled from the surface in the vicinity of the wraps. The specimen's stiffness was significantly decreased by separation of the FRP L-shaped due to buckling. Then in the drift $2 \%$, the compressive concrete crushed and the cracks above the L-shaped strength at the right hand side of the beam began to open. Finally in the drift 4\%, L-shaped beams tore longitudinally. As it is displayed in Figure 7, the load-displacement curve of the specimen is more inclined than that of the previous specimens which caused the decrease of stiffness and strength of the NS5R specimen compared to the previous specimens. Also due to the slide of the beam's longitudinal reinforcements and separation of FRP from the concrete's surface, pinching was clearly observable.

Figure 9 briefly compares the specimens' moment-carrying capacities in reversed cyclic loading with that of NS5 specimen.

The summary of load carrying capacity for specimens is presented in Table 1. According to the last column of Table 1, among the specimens that have achieved the capacity of the final drift $5 \%$, only NS5R specimen has a lower load-carrying capacity than the basis NS5 specimen. In addition, the initial stiffness of NS1R and NS2R are very similar to that for specimen NS5.

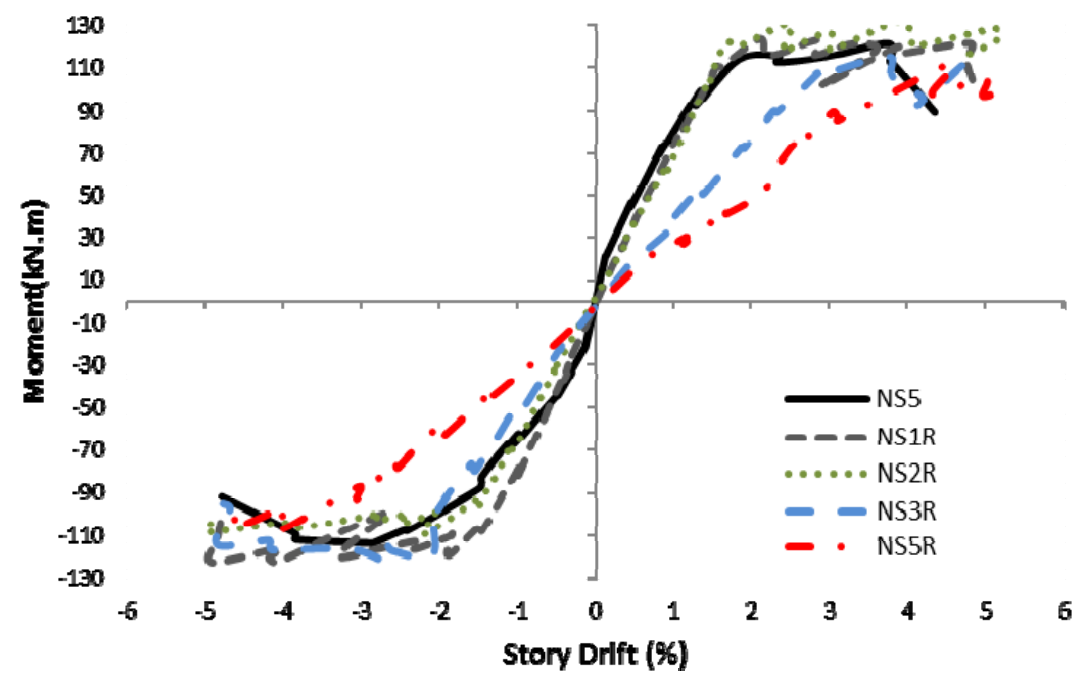

Figure 9: Moment-Storey drift envelopes of reference and strengthened specimens. 


\begin{tabular}{ccccccc}
\hline \hline Joint ID & $\begin{array}{c}\text { Maximum } \\
\text { Storey Drift } \\
(\%)\end{array}$ & $\begin{array}{c}\text { Forward } \\
\text { Capacity } \\
(\mathrm{C}+)(\mathrm{kN})\end{array}$ & $\begin{array}{c}\text { Backward } \\
\text { Capacity } \\
(\mathrm{C}-)(\mathrm{kN})\end{array}$ & $\begin{array}{c}\text { Ratio }(+) \\
(\mathrm{C} / \mathrm{C} \text { N55 })\end{array}$ & $\begin{array}{c}\text { Ratio (-) } \\
(\mathrm{C} / \text { CNS5) }\end{array}$ & Mean Value \\
\hline NS5 (base) & 5 & 81.26 & -82.98 & 1 & 1 & 1 \\
NS1 & 1 & 53.95 & -53.89 & 0.66 & 0.65 & 0.66 \\
NS2 & 1.5 & 65.48 & -58.4 & 0.81 & 0.7 & 0.75 \\
NS3 & 3 & 80.5 & -79.52 & 0.99 & 0.96 & 0.97 \\
NS1R & 5 & 86.75 & -85.74 & 1.07 & 1.03 & 1.05 \\
NS2R & 5 & 92.41 & -76.81 & 1.14 & 0.93 & 1.03 \\
NS3R & 5 & 80.87 & -87.29 & 1 & 1.05 & 1.02 \\
NS5R & 5 & 78.3 & -75.68 & 0.96 & 0.91 & 0.94 \\
\hline \hline
\end{tabular}

Table 1: Load carrying capacity of specimens in forward and backward loading.

\section{COMPARISON AND DISCUSSION OF TEST RESULTS}

\subsection{Moment-Curvature}

Curvature and rotation at the joint as well as the beam critical zone (distance of $2 h$ from the side of joint where $h$ is the height of the beam cross section) were measured during the experiment. The beam section curvature was measured by the $150 \mathrm{~mm}$ LVDT installed at $600 \mathrm{~mm}$ from the joint face in terms of the following formulation. Using curvature, the longitudinal strain can be obtained at the beam critical sections and the yield of reinforcements can be controlled.

If the displacement of the LVDT installed at $2 h=600 \mathrm{~mm}$ from the joint face is denoted by $\Delta$, it must be noted that the deformation resulted from the rotation of the joint must be subtracted from $\Delta$ value. This is done by reducing the rotation of the joint multiplied by $2 h$. Assume that the rotation of the joint is $\theta_{j}$, the beam's net displacement at $600 \mathrm{~mm}$ that is denoted by $\Delta_{n e t}$ is obtained from the Equation (1). If it can be assumed that the beam deforms as a circle in its critical zone, the circle radius $(\mathrm{R})$ can be obtained from the circle Equation as Equation (2) and the curvature can be computed from $1 / \mathrm{R}$ (see Figure 10).

Using Equation (3), the circle radius can be determined from the circle relation and the beam curvature can be obtained by the Equation (4).

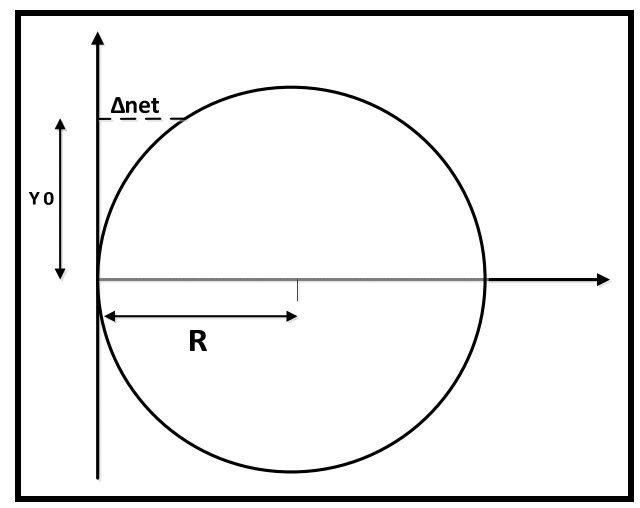

Figure 10: Circular deformation of beam and definition of R. 


$$
\begin{gathered}
\Delta_{\text {net }}=\Delta-600 \theta_{j} \\
\left(\Delta_{\text {net }}-R\right)^{2}+y_{0}{ }^{2}=R^{2} \\
R=\frac{\Delta_{\text {net }}{ }^{2}+y_{0}^{2}}{2 \Delta_{\text {net }}} \\
\phi=\frac{1}{R}=\frac{2 \Delta_{\text {net }}}{\Delta_{\text {net }}{ }^{2}+y_{0}{ }^{2}}
\end{gathered}
$$

Where, $\mathrm{R}$ is the circle radius, $y_{0}$ is the critical length of the beam $(2 h)$ and $\phi$ is the curvature of beam section. Since the curvature is directly related to the strain, the beam strain at the vicinity of the joint can be obtained from the Equation (5).

$$
\begin{gathered}
\phi=\frac{\varepsilon}{C} \\
\varepsilon=\frac{2 \Delta_{\text {net }} \cdot C}{\Delta_{\text {net }}{ }^{2}+y_{0}{ }^{2}}
\end{gathered}
$$

Where, $\varepsilon$ is the section strain and $C$ is the distance of any section string from the section neutral axis. Since the bending is symmetrically applied to the beam in two directions, it can be assumed that cracking is the same at both sides of the section and the neutral axis of the beam remain in section middle axis.

According to the formulation that was mentioned above, moment-curvature curves are plotted in Figure 11. All strengthened specimens had a curvature more than reference specimen. As displayed in Figure 11, NS1R specimen has a higher load-carrying capacity and curvature than the NS5 specimen. In NS2R specimen, curvature is the same of specimen NS1R and its load-carrying capacity is higher than that of NS5 specimen. Higher strength in NS3R specimen did not reduce the curvature but increased the load-carrying capacity. Due to the higher damage of NS5R specimen, the curvature increased more than twice that of other strengthened specimens. Therefore, it is concluded that the retrofitting system increases the load-carrying and the curvature of the beam connected to the joint compared to the reference specimen.

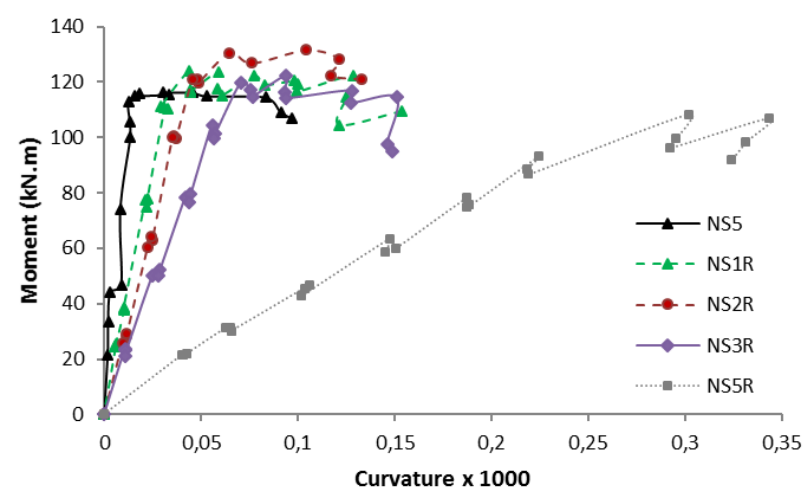

Figure 11: Moment - Curvature curve of beam's section. 


\subsection{Plastic Rotation}

The plastic rotation is plotted against moment and storey drift in separated curves of Figure 12. If the rotation in the elastic range is subtracted from the whole rotation, the plastic rotation will be obtained. This is performed in Excel spreadsheet program. Rotation is obtained at the core of the joint and in the beam critical zone by different LVDTs mounted in proper positions. Figure 12 shows that although all the tested joints had the same loading history, plastic rotation in the NS5 specimen beam was more than that of the strengthened specimens. In other words, strengthening the damaged joints by FRP layers, the plastic rotation of the joint and the damaged zones around it were decreased. This is due to the elastic nature of FRP materials. Also, Figure 12 shows that the plastic rotations of the beams in strengthened specimens were reduced in each storey drift in compared with reference specimen.

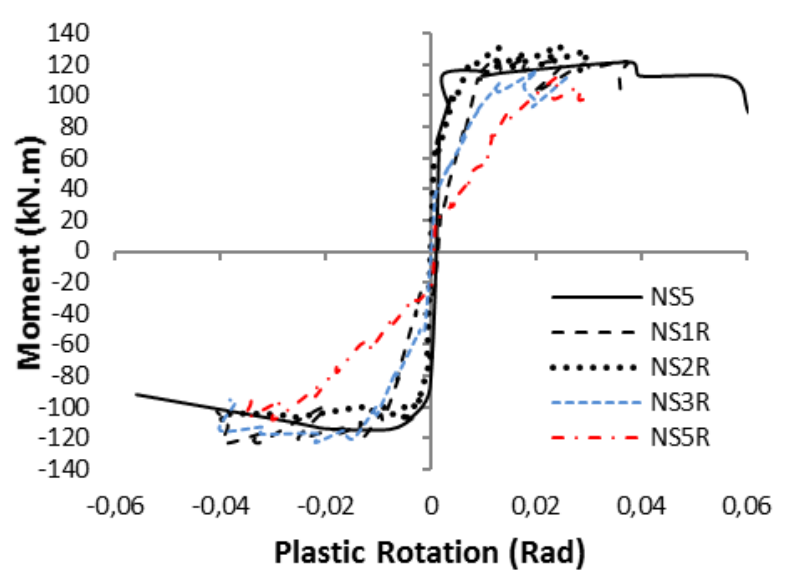

(a)

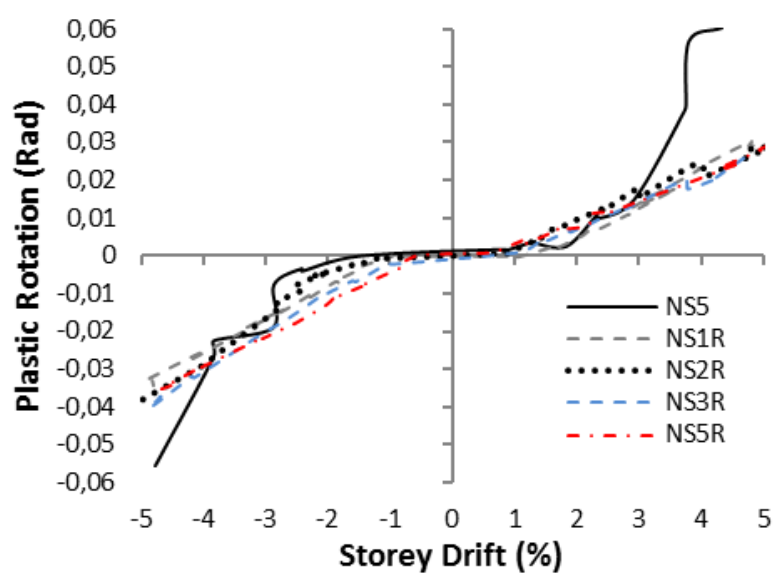

(b)

Figure 12: Plastic rotation of the beam's plastic hinge

Since the structural performance levels are determined from the plastic rotation of beams and columns, beam and column plastic rotation-moment curves are used to evaluate of the joint performance levels in the following section.

\subsection{Performance Levels}

According to the Tables 6-6 and 7-6 of FEMA 273 (1997) that is presented in Table 2, having the plastic rotation in the members, the damage levels can be computed for any member. According to the Table, beam and column as the main members in the structure's lateral load resistance experience a new performance level when they achieve a special plastic rotation.

When the strengthening system can resist the plastic rotation up to the level of life safety without major decrease in the load-carrying capacity (less than 10\%), the structure have acceptable performance. 


\begin{tabular}{|c|c|c|c|c|c|}
\hline \multicolumn{3}{|c|}{ Conditions } & \multicolumn{3}{|c|}{ Plastic Rotation Angle, radians } \\
\hline \multicolumn{3}{|c|}{ Columns controlled by flexure } & \multicolumn{3}{|c|}{ Primary Component } \\
\hline \multirow{2}{*}{$P / A_{g} f_{c}^{\prime}$} & \multirow{2}{*}{ Trans. Reinf. } & \multirow{2}{*}{$V / b_{w} d \sqrt{f_{c}^{\prime}}$} & \multicolumn{3}{|c|}{ Performance Level } \\
\hline & & & $\mathrm{IO}$ & LS & $\mathrm{CP}$ \\
\hline$\leq 0.1$ & $\mathrm{NC}$ & $\leq 3$ & 0.005 & 0.005 & 0.01 \\
\hline \multicolumn{3}{|c|}{ Beams controlled by flexure } & \multicolumn{3}{|c|}{ Primary Component } \\
\hline \multirow{2}{*}{$\left(\rho-\rho^{\prime}\right) / \rho_{b a l}$} & \multirow{2}{*}{ Trans. Reinf. } & \multirow{2}{*}{$V / b_{w} d \sqrt{f_{c}^{\prime}}$} & \multicolumn{3}{|c|}{ Performance Level } \\
\hline & & & IO & LS & $\mathrm{CP}$ \\
\hline$\leq 0.0$ & $\mathrm{NC}$ & $\leq 3$ & 0.005 & 0.01 & 0.02 \\
\hline
\end{tabular}

Table 2: The plastic rotation expected in different performance levels according to FEMA 273 (1997).

Analysis of the test results showed that the joint performance level is determined by the plastic hinge located in the end of the beam that is compatible with the weak beam-strong column theory. The load capacity and storey drift related to each performance level of specimens is presented in Table 3. According to Table 3, the higher the specimen's capacity and drift are at any performance level, the more acceptable behavior they achieve. It is clear that all specimens have a higher or equal capacity in compare with specimen NS5. NS1R specimen retained the load-carrying capacity and the lateral displacement (drift) higher than those of the reference specimen at any level of performance. Also, NS2R specimen performed an acceptable behavior at any level of performance, especially in terms of the load-carrying capacity. NS3R had an acceptable behavior up to IO performance level. But since it had a higher initial damage than NS1R and NS2R specimens, it showed a lower load-carrying capacity after IO level. The performance levels of NS5R specimen occurred in lower drifts compared with the reference specimen. The specimen load-carrying capacity also decreased to $24 \%$ in compare with the reference joint.

\begin{tabular}{ccccccccccccc}
\hline \hline \multirow{3}{*}{$\begin{array}{c}\text { Specimen } \\
\text { ID }\end{array}$} & $\begin{array}{c}\text { Drift } \\
\%\end{array}$ & $\begin{array}{c}\text { Capacity } \\
(\mathrm{kN} . \mathrm{m})\end{array}$ & \multicolumn{1}{c}{ Ratio to NS5 } & \multicolumn{4}{c}{ LS Level } & \multicolumn{4}{c}{ CP Level } \\
& Drif Capacity & $\begin{array}{c}\text { Drift } \\
\%\end{array}$ & $\begin{array}{c}\text { Capacity } \\
(\mathrm{kN} . \mathrm{m})\end{array}$ & $\begin{array}{c}\text { Ratio to NS5 } \\
\text { Drif Capacity }\end{array}$ & $\begin{array}{c}\text { Drift } \\
\%\end{array}$ & $\begin{array}{c}\text { Capacity } \\
(\mathrm{kN} . \mathrm{m})\end{array}$ & $\begin{array}{c}\text { Ratio to NS5 } \\
\text { Drif Capacity }\end{array}$ \\
\hline NS5 & 0.44 & 43 & 1 & 1 & 1.82 & 107.35 & 1 & 1 & 3.07 & 115.15 & 1 & 1 \\
NS1R & 0.91 & 67 & 2.06 & 1.56 & 1.84 & 117 & 1.01 & 1.09 & 3.14 & 120 & 1.02 & 1.04 \\
NS2R & 0.65 & 46 & 0.72 & 1.07 & 1.43 & 101.47 & 0.78 & 0.95 & 2.75 & 120 & 0.81 & 1.04 \\
NS3R & 1.05 & 27 & 2.39 & 0.63 & 1.48 & 59 & 0.81 & 0.55 & 3.75 & 114 & 1.22 & 0.99 \\
NS5R & 0.63 & 19 & 1.43 & 0.44 & 1.36 & 35 & 0.75 & 0.33 & 3.1 & 86.95 & 1.01 & 0.76 \\
\hline \hline
\end{tabular}

Table 3: Performance levels of tested B-C joints.

Based on the results, it is proved that behavior of two strengthened specimens, i.e. NS1R and NS2R, improves the both performance level and load carrying capacity, simultaneously. Therefore, the damage level of beam-column connection up to 1.5\% drift ratio (as for the NS2R specimen) is considered as the drift which can be repaired by strengthening using FRP laminates. This is called the repairability level for the tested joints with the used strengthening system. 


\subsection{Ductility Ratio}

Ductility can be described as the ability of the structure or its components, or of the materials used to offer resistance in the inelastic domain of response. It includes the ability to sustain large deformations, and a capacity to dissipate energy by a hysteretic behavior.

The definition of ductility ratio can be expressed on the member section by $\phi_{u} / \phi_{y}$ and also on the structural member by $\theta_{u} / \theta_{y}$ or $\delta_{u} / \delta_{y}$, where $\phi, \theta$ and $\delta$ are curvature, rotation and displacement, respectively.

The section curvature in the beam of tested joints is obtained by Equation (4). Also assuming the beam to column joint as a unit member the ductility ratio of the tested joints can be computed using the rotation produced on the beam and the lateral displacement of the beam tip, respectively.

The concepts of the joint yielding and the ultimate limit can't be clearly observed from their hysteresis behavior. This uncertainty can be attributed to the gradual cracking or yielding of the joint elements around the yield point. In this work, the definitions by Pauly and Pristly (1992) and Trong et al. (2010) are used to determine the joint yielding and ultimate limit, respectively.

In the calculation of ductility factors under monotonic loading, it is difficult to find the amount of yield displacement, since the load-deformation curve may not present a well-defined yielding point. This may occur, for example, due to yielding in different parts of a structure commencing at different load levels or due to non-linear behavior of the materials. For routine design computations, a bilinear approximation shown in Figure 13 may also be used where the yield displacement, $D_{y}$ is $4 / 3$ of the displacement at a load of about $0.75 P_{y}$, where $P y$ defines the yield strength of the member (Paulay and Priestley 1992).

Ultimate displacement, $D_{u}$ is defined as the displacement corresponding to a $10 \%$ strength degradation of the maximum strength $\left(P_{\max }\right)$ of the specimen; the yield displacement, $D_{y}$ was the displacement value corresponding to the first yielding of the longitudinal beam reinforcements (LeTrung, Lee et al. 2010).

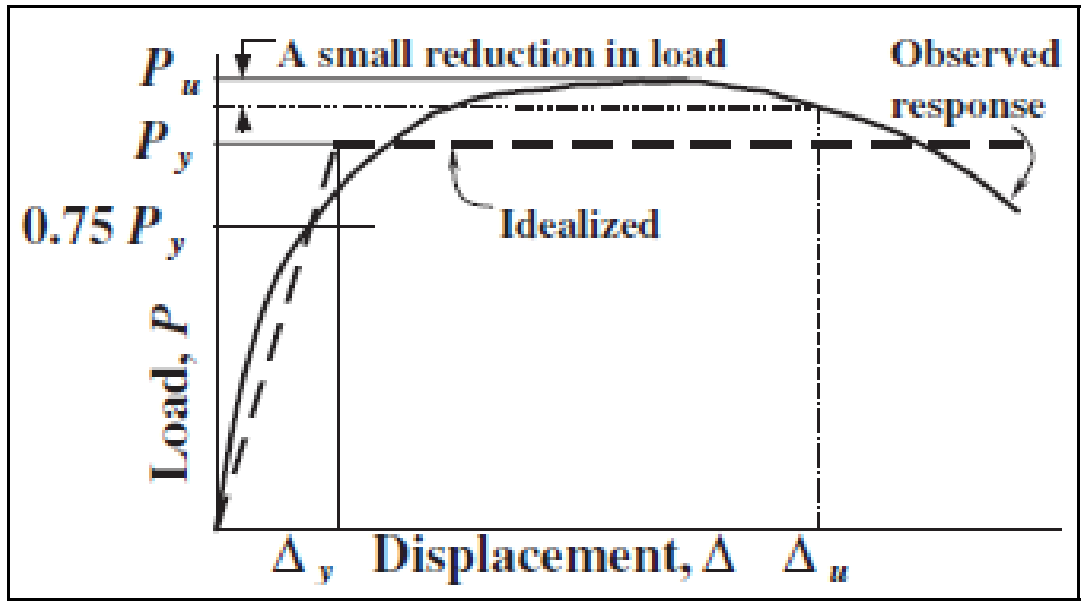

Figure 13: Definition of yielding limit of structure by use of idealization concept (Paulay and Priestley 1992). 
Generally, using the strengthening system can increase the capacity, ductility or both of them. In this research, when the joints were strengthened, their capacity increased. The ductility ratio is computed at the joint and beam section according to Table 4. Table 4 shows that using FRP layers, the connection ductility decreases both at section and joint member. This result is consistent with those by Dalalbashi et al. (2012) and Attari et al. (2010). More decrease is expected as the initial damage of the joints is increased. Therefore, the ductility ratio of the specimens NS1R, NS2R, NS3R and NS5R has decreased compared to the reference specimen up to $10 \%, 20 \%, 40 \%$ and $50 \%$, respectively.

\begin{tabular}{ccccccc}
\hline \hline \multirow{2}{*}{ Joint ID } & \multicolumn{5}{c}{ Section Ductility for Beam of the B-C joint } & Ratio \\
& $\mathrm{M}_{\max }$ & $0.9 * \mathrm{M}_{\max }$ & $\phi_{y}{ }^{*} 1000$ & $\phi_{u}{ }^{*} 1000$ & $\phi_{u} / \phi_{y}$ & $\mu / \mu_{\text {NS5 }}$ \\
\hline NS5 & 106.6 & 95.94 & 0.031 & 0.0971 & 3.13 & 1 \\
NS1R & 123.8 & 111.42 & 0.044 & 0.125 & 2.84 & 0.91 \\
NS2R & 131.57 & 118.413 & 0.048 & 0.132 & 2.75 & 0.88 \\
NS3R & 122.35 & 110.115 & 0.07 & 0.127 & 1.81 & 0.58 \\
NS5R & 111.97 & 100.773 & 0.224 & 0.292 & 1.3 & 0.42 \\
\hline
\end{tabular}

Element Ductility for B-C Joint

\begin{tabular}{ccccccccc} 
Joint ID & $\delta_{y}$ & $\theta_{y}$ & $\delta_{u}$ & $\theta_{u}$ & $\delta_{u} / \delta_{y}$ & $\theta_{u} / \theta_{y}$ & $\mu /\left.\mu_{N S 5}\right|_{\delta}$ & $\mu /\left.\mu_{N S 5}\right|_{\theta}$ \\
\hline NS5 & 21.39 & 0.0197 & 71.5 & 0.0617 & 3.34 & 3.13 & 1 & 1 \\
NS1R & 25.27 & 0.0121 & 71.5 & 0.037 & 2.83 & 3.06 & 0.91 & 0.98 \\
NS2R & 25.7 & 0.0118 & 71.5 & 0.0292 & 2.78 & 2.47 & 0.74 & 0.79 \\
NS3R & 40.55 & 0.0127 & 71.5 & 0.0255 & 1.76 & 2.01 & 0.6 & 0.64 \\
NS5R & 42.9 & 0.0195 & 71.11 & 0.0338 & 1.66 & 1.73 & 0.52 & 0.55 \\
\hline \hline
\end{tabular}

Table 4: Ductility ratio in the section and joint element.

\section{CONCLUSIONS}

In this paper, the results of some tests on FRP strengthening technique of damaged beam-column joints were presented. C-FRP sheets were used to wrap the critical regions of the beam, column and the joint zone of the examined sub-assemblages for confining these regions. The results showed that the method is effective and capable of restoring or even upgrading load-carrying capacity and initial stiffness of damaged joints. The performance level of damaged joints under cyclic tests was also improved. The repair ability level of damage was also evaluated up to $1.5 \%$ drift ratio for tested B$\mathrm{C}$ joints. Nevertheless, the plastic rotation and ductility ratio of critical beam section and the joint area were decreased due to elastic nature of FRP materials. Finally the application of other methods for strengthening of the concrete structures can be investigated in the future.

\section{References}

ACI440.2R-08 (2008). Guide for the design and construction of externally bonded FRP system for strengthening concrete structures. ACI 440.2R-08. Michigan (USA). 440-02. 
Antonopoulos, C. P. and T. C. Triantafillou (2002). "Analysis of FRP-strengthened RC beam-column joints." Journal of composites for construction 6(1): 41-51.

CSA A23. 3-04 (2004). "Design of concrete structures" CSA, Rexdale, Ontario.

Attari, N., S. Amziane and M. Chemrouk (2010). "Efficiency of beam-column joint strengthened by FRP laminates." Advanced Composite Materials 19(2): 171-183.

Balsamo, A., A. Colombo, G. Manfredi, P. Negro and A. Prota (2005). "Seismic behavior of a full-scale RC frame repaired using CFRP laminates." Engineering Structures 27(5): 769-780.

Dalalbashi, A., A. Eslami and H. Ronagh (2012). "Plastic hinge relocation in RC joints as an alternative method of retrofitting using FRP." Composite Structures 94(8): 2433-2439.

FEMA 273 (1997). "NEHRP Guidelines for the seismic rehabilitation of buildings." Federal Emergency Management Agency. Washington, D.C. (USA).

Ilki, A., I. Bedirhanoglu and N. Kumbasar (2010). "Behavior of FRP-retrofitted joints built with plain bars and lowstrength concrete." Journal of Composites for Construction 15(3): 312-326.

Le-Trung, K., K. Lee, J. Lee, D. H. Lee and S. Woo (2010). "Experimental study of RC beam-column joints strengthened using CFRP composites." Composites Part B: Engineering 41(1): 76-85.

Li, B. and Q. Kai (2010). "Seismic behavior of reinforced concrete interior beam-wide column joints repaired using FRP." Journal of Composites for Construction 15(3): 327-338.

Li, J., B. Samali, L. Ye and S. Bakoss (2002). "Behaviour of concrete beam-column connections reinforced with hybrid FRP sheet." Composite Structures 57(1): 357-365.

Pantelides, C. P., Y. Okahashi and L. Reaveley (2008). "Seismic rehabilitation of reinforced concrete frame interior beam-column joints with FRP composites." Journal of Composites for Construction 12(4): 435-445.

Park, R. and T. Paulay (1975). Reinforced Concrete Structures. Wiley, New York.

Paulay, T. and M. Priestley (1992). Seismic design of reinforced concrete and masonry buildings. John Wiley and Sons, New York.

Rizkalla, S., T. Hassan and N. Hassan (2003). "Design recommendations for the use of FRP for reinforcement and strengthening of concrete structures." Progress in Structural Engineering and Materials 5(1): 16-28. 